\title{
DIALECTIC INTERACTION OF QUANTITY, QUALITY AND RELATION IN SIMILE DOMAIN
}

\author{
Mariana Oleniak \\ Vasyl`Stus Donetsk National University, Vinnytsia, Ukraine \\ maryana@mail.org
}

\begin{abstract}
This paper attempts to shed some light on the problem of correlation of such ontological categories as quality, quantity and relation in similes. The matter in question is significant since it relates to the problem of anthropocentrism in language. It shows the speaker's attitude to the information encoded in a simile by consciously choosing a vehicle via measuring a tenor's salient feature against an implied abstract scale of objects, notions, phenomena, etc. that possess a particular quality to a certain extent. The nature of the ground of simile is described to be gradable, capable of being subjectively measured from the perspective of the speaker's environmental perception. The gradability of a shared feature shown as a scale of potential vehicles lends itself to the interpretation as a fragment of the linguistic worldview displaying a range of scale markers typical of a certain linguistic community in a certain historical period of time. The polar opposite notions on an implied scale are depicted to represent a (proto/stereo) type and an anti(proto/stereo)type typical of certain linguo-cultural domains in a particular fragment of a linguistic worldview. By moving from the explanatory examples to the analysis of empirical material the author concludes that the categories of quantity, quality and relation are intrinsic in every simile and manifest themselves in the choice of a tenor-vehicle pair that do not exist within simile other than in relation to each-other. The material described in the article serves as an evidence of language dependence on historical and social parameters. The paper explains the mechanism of creation of the congruous and ironic similes according to the universal process of simile formation where the unity of quantity, quality and relation are the key factors of its existence.
\end{abstract}

Keywords: simile; gradability; quality; quantity; linguistic worldview; formula.

\section{Introduction}

It has been many centuries since the ten fundamental ontological categories, among which quality, quantity and relation being particularly significant, were singled out by Aristotle to be interpreted by numerous philosophers, and also by many linguists who understood that language and speech are the reflection of all social processes displaying the societal development. This article is an attempt to explicate connections between quality, quantity and relation to a linguistic dimension of simile putting forward several stimulating ideas regarding the principles of the choice of vehicle. Beginning with the description of theoretical and methodological background, this research provides the interpretation of the three categories in question. The hypothesis of the research is that simile represents the dialectal unity of the three ontological categories that manifest themselves in the preference of a tenor-vehicle co-selection. First, I support my hypothesis with the help of some straightforward simile examples and the one taken from the earlier period of English showing that the preference of a tenor-vehicle co-selection depends on historical and social parameters. Later, all the inferences are confirmed by persuasive empirical material sampled from Similes Dictionary (Sommer, 2013). I analyse the concrete empirical examples in terms of the dialectic unity of quantity, quality and relation within a simile resorting to the subjective abstract scale of gradable "quiet as" similes and the universal formula for similes which is $A n \approx \mathrm{B}^{\mathrm{n}}$. In this formula $A$ is a tenor, $n$ is a ground, a commonly shared feature by a tenor and a vehicle, $B$ is a vehicle (all representing quantity-quality unity); $\approx$ is a symbol encoding the similarity between the tenor and the vehicle which represents relation; the operations of multiplication and exponentiation represent different quantity of a certain feature in a tenor and a vehicle (Oleniak, 2018). I also highlight the mechanism of an ironic simile creation.

\section{Theoretical and methodological background}

The categories of quality, quantity and relation are regarded here in their linguistic domain, therefore, in this article I follow the works of such linguists as Baudouin de Courtenay (1963), Bondarko (1996), Di Paolo (2018), Cuffari (2018), De Jaegher (2018), Jespersen (1958), Shvachko (2007), Panfilov (1977), Caws (1993), Remijsen (2014), Nauta (2004), who dealt with these categories in different branches of linguistics, and consider that the three categories in question should be interpreted in terms of their interrelation and interconnectedness as highly abstract concepts not expressed by exact numerical values but as characterising certain mental images having particular features.

The aim of this paper is to show that a tight connection between quality, quantity and relation reveals itself in the gradable nature of a salient feature of a simile. Gradability of a salient feature is considered both as a mental process as well as a result embodied in a simile per se. The problem of scale of likeness and exaggeration was also highlighted by Barnden (2015).

Oleniak, M. (2019). Dialectic interaction of quantity, quality and relation in simile domain. Advanced Education, 12, 134-141. DOI: $10.20535 / 2410-8286.153366$ 
In the logical-philosophical sense, quality is the internal certainty of objects and phenomena, the sum total of their essential features, which actually makes them certain objects and phenomena. Aristotle defined it as a distinguishing feature of a genera, he highlighted the variability of quality as the state of things, their ability to turn into the opposite. Quantity is an external characteristic of objects and phenomena, which outlines them by the degree of the development of properties: volume, number, speed, etc. The attempts to analyse the problem of quantity besides Aristotle were made by the Pythagoreans in the study of the nature of numbers and their use in the process of the environmental cognition. Later, such philosophers as Descartes, Newton and Leibniz developed a rather generalised notion of quantity, including both constants and variables in it, as well as its relation to order and comparison (PhED, p. 263). Nevertheless, the first to consider the principle of the quantity to quality transitions was Hegel. The category of relation has also triggered much of interpretation still being in the focus of research, among which are Duncombe (2015), Hood (2004), Long (2007). It seems like the Aristotelian pros ti, the literal translation of which is "in relation to something", is yet to receive its commonly-accepted reading.

In the functional grammar theory, the comparability is interpreted as "an independent field, which occupies an intermediate position between the fields of quantity and quality (overlapping with both)" (Bondarko, 1996, p. 8-9).

In this paper the categories in question are not treated from classical logico-philosophical standpoint, but as the ones whose dialectic unity enters a linguistic domain being a key principle where a specific vehicle is chosen for a simile. Thus, the abovementioned definitions of quantity and quality, accepted in logicophilosophical studies, hold true for this paper as well. I use the term relation in its broadest sense, equivalent to Aristotelian pros ti, describing a correlation, an association, a link between a tenor and a vehicle.

\section{Methods}

The method used in this research is mainly induction: from concrete language actualisation of poetic comparison to the establishment of dialectic connection among its semantic constituents by generalising theoretical findings and drawing conclusions. Descriptive, comparative and correlative analysis methods were used while interpreting the examples provided to depict the dialectic unity of ontological categories of quantity, quality and relation. The mathematical modelling method was used to describe the peculiarities of an ironic simile in comparison to a non-ironic one.

\section{Materials and procedure}

The outline of the paper is threefold. I will preface the discussion with a brief account of the universal nature of simile creation process and its connection with time and linguo-cultural distinctiveness. To exemplify the issue, I will put forward a contrasting description of one and the same notion in different periods of English as well as randomly chosen present-day contexts in three languages. Next, I will proceed with the explanation of a quantity-quality interaction within similes by designing and commenting on the scale of beauty gradation as a potential list of "beautiful as" simile vehicles. Finally, I will confirm my inferences by analysing the sampling of "quiet as" similes harvested from contemporary dictionary of similes by Frank J. Wilstach comprising over 16000 similes taken from about 2000 literature sources.

\section{Results and Discussion}

Recording human thinking, language and speech serve as evidence of the specifics of the actualisation of ontological categories revealing the human understanding of the environment and a person's place in it via evaluating, measuring and comparing. These processes yield linguistic results showing the individual combination of cognitive features being the fundamentals of peoples' insertions, mental images, and, subsequently, language nominations based on the latter.

\section{The universal and the individual in a simile formation process}

I approach the problem of a simile from the theoretical standpoint that every simile starts its existence according to a universal simile forming process and the assumption that the result of this process will manifest itself through the speaker's choices in speech, that is, through the actualisation of a specific individual version of similitude. By a universal simile forming process I mean the speaker's preference for selecting a certain object/notion/phenomenon, etc. rather than others to serve as a simile vehicle, capable for a tenor characterisation by pointing at the distinctive nature or its features.

Every nation, society, community, even every speaker has formed a range of individual associations built up over the period of their existence, which might not (and usually does not completely) coincide with the associations that others have correspondingly built. This difference does not concern so much the items at one's disposal, but rather the choices made by the representatives of these nations, societies, communities 
and speakers. Accordingly, inasmuch as any speaker can seemingly use any object / notion / phenomenon, etc. for a vehicle, in fact, they are prone to make prototypical idiosyncratic choices or stereotypical ones for a certain community in a certain period of time by subjective evaluation of the compared items. In this paper, I distinguish between a prototype and a stereotype asserting that both of them can be the tools for the creation of similes. By a stereotype, I mean a universally accepted opinion, image or generalisation based on a nation's experience. Inasmuch as stereotype presupposes some generally agreed characterisation; prototype, in my opinion, is more individual, it presupposes creation of something similar to the sample. Since simile vehicles do not always reflect universally accepted opinions but oftentimes represent the author's idiosyncratic choices, both terms are used in the paper. Indeed, the transition of a prototype into a stereotype demands additional research, which goes beyond the limits of this article. The evaluation rests on the analysis of tenor-vehicle common typical qualities(s) and (mainly sub-)conscious scrutiny of the uneven concentration of this quality in each of the items, which identifies them as potential candidates to be compared. This is exactly where the ratio of quantity and quality in two related notions becomes critical. The non-random choice of a vehicle and a certain tendency for a co-selection of a tenor-vehicle pair can be proved by the possibility to compile dictionaries of similes (see Wilstach, 2017; Sommer, 2013). It does not mean, of course, that every recorded list of similes is identical and exhaustive, but sooner presupposes a strong tendency to display similar associations. Nevertheless, the study of similes as the reflection of speakers' linguo-cultural peculiarities can provide fascinating clues about their understanding of the environment, which is confirmed by Musolff et al (2014) and Lei (2016).

Simile displays a person's cognitive-evaluative attitude to the environment by comparing a tenor to a vehicle on the grounds that they share a common salient feature. As a result of such kind of mental activity, the choice of the vehicle is made showing an individual, special subjective interpretation of the world which correlates with the collective perception of the state of things. Thus, aiming to describe a very quick reaction, an Englishman will choose a flash or a wink for a vehicle (e.g. quick as a flash, quick as a wink) while a Ukrainian will opt for lightning or wind (e.g. швидкий як блискавка 'quick as lightning', швидкий як вітер 'quick as wind') and in Polish the vehicle will be an eagle (e.g. szybki jako orzet 'as quick as an eagle'). The choice of a vehicle defines a peculiar view on the state of reality showing a linguo-cultural ability to interpret the concepts in terms of qualitative and quantitative characteristics. The typicality of simile vehicle choice was also highlighted by Sommer: "One could compile a small book of just "Clear as" similes. The bell comparison along with "Clear as a whistle" and "Clear as crystal" are probably most frequently used and familiar" (Sommer, 2013, p. 121). The difference in vehicle choice preferences by different language communities will become even more plausible given the fact that in other speaking communities, Ukrainian for example, one would hardly come across the association of clarity with a whistle or a bell.

The choice of the vehicle represents conceptual understanding, logical in character, derived from the mental imagery dealing with the qualitative and quantitative parameters of an object, phenomenon, process, event etc., objectively representing the speaker's attitude to the tenor. For example, in a simile The movie is as exciting as a commercial for washing powder the speaker, assigning certain qualitative-quantitative ratios of the ground (exciting) to the tenor (movie) and the vehicle (a commercial for washing powder), displays his/her negative attitude to the film.

In search for a suitable vehicle, the speaker selects from a wide range of potential objects, notions, phenomena etc., deciding on the one that, according to him/her, is specific enough against the background of everything else. What makes it specific is some quality distinguishing its essential properties that are taken for granted in a certain period of time by a certain language community, which may change over time. This is why it was quite natural to compare a talkative person to an unprotected city for an Old English speaker (Swa hit awriten is on Salomonnes cwidum datte se mon se ðe ne mog his tungan gehealdan sie gelicost openre byrig, ðcere ðe mid nane wealle ne bið ymbworht. (Pastoral Care, p. 276) 'As it is written in the proverbs of Solomon, the man who cannot hold his tongue is most like an unprotected city, with no surrounding walls') which would not be the case in PDE, since the city without walls would not cause a direct association with danger any more, let alone the relative absence of such danger due to the freedom of speech in modern English-speaking communities which questions the necessity of such simile in the first place. This particular essential quality (a perilous state), attributed to the vehicle (city without walls) is inseparable from it and exists within the limits of this very precise object during a certain timeframe. By losing its quality overtime as a result of the historical process of unification of cities into bigger states, it stops to be suitable for the vehicle and ceases to exist as a prototype to represent a salient feature of danger. 


\section{A gradability scale of a simile ground}

The dialectic interaction between quantity and quality reveals itself in simile domain in its philosophical embodiment, namely in the law of the transformation of quantity into quality. Quantity and quality represent an inseparable unity in objects and phenomena: the notion of quality makes it possible to fix the moment of stability in things; the notion of quantity provides an opportunity to show the variability of things. Changing the quantity of any element's dynamics naturally leads to the transition of this element to a static qualitatively different level proving its gradability. The interaction of the conceptual categories of quality and quantity, which in their unity indicate a gradable intensity of the feature, forms the ground for similes. Quantity and quality exist in unity in a tenor and a vehicle, basically forming them, which is witnessed by its inevitable transformation into a different tenor and a vehicle if one of them changes. Every qualitative state of a tenor or a vehicle is defined by a certain level of quantity, the limits of which, if surpassed, change their quality creating a new object/notion/phenomenon etc. The co-dependency of quantity and quality in a vehicle calls for a dialectic perspective on their coexistence where a specific ratio between them accounts for a (proto/stereo)type or anti-(proto/stereo)type chosen as a vehicle for a simile. However, this (proto/stereo)type or anti-(proto/stereo)type can be called a simile vehicle only in the instance that it exists in consistency with a tenor, otherwise it is just another object/notion/phenomenon etc. outside a simile. In other words, it becomes a part of a simile only when it is related to a tenor. This is how the categories of quantity and quality form a dialectic connection with the category of relation within a simile: There can be no simile without a relation of a tenor to a vehicle with both being nothing more than a quantity-quality unity.

A relative category in nature, the concept of quality is always gradable, which holds true for the simile domain as well. It has its implied scale and takes certain shapes representing its uneven intensity in a tenor and a vehicle. By relating the latter, we understand the different degree of intensity of the quality shared by them, and, bearing in mind a certain stereotype as a standard of the measurement, we subjectively establish the quantitative aspect of the shared quality.

The quantitative aspect of simile is not meant to be described in exact numbers, it is rather a sense of measure a speaker has in everything: be it beauty, behaviour, shapes and forms, relationships, etc. Rather than having a numerical value, it embodies the Protagoras's statement "Man is the measure of all things" interpreted by Plato as the truth being what individuals deem it to be. Developing the topic of a talkative person, the following examples can be provided showing a modern Englishmen's sense of the measure of talkativeness: as talkative as a parrot and as talkative as a Finn, where the image of a parrot stands in the opposition to the image of an average Finn. They both represent the polar opposite notions on an implied scale of talkativeness capable of displaying subjective measuring (from the most talkative to the least talkative). The dialectic unity of quality and quantity constitute this measure while the subjective character of it rests on the relativity of their ratio. While choosing a potential candidate for a simile vehicle the speaker subconsciously measures a tenor's salient feature against an abstract gradation scale moving from the ground zero point, typical for his/her linguistic worldview governed by psychological, intellectual, evaluative, etc. aspects, up or down the scale. The vector of movement is directly connected with the communicative intention of a speaker: in case of a congruous non-ironic simile the movement will be upward, towards the apex marker denoted by an object, notion, phenomenon, etc. possessing the "biggest amount of a trait" in question. However, if a speaker wants to be ironic, s/he will move downwards, towards the bottom marker denoted by an object, notion, phenomenon, etc. possessing the "least amount of a trait" in question.

The choice of the vehicle along the scale of the simile ground quality is motivated by a context as well as social and individual characteristics of the speaker (psychological, intellectual, emotional, etc.). Being historically, socially and situationally dependent, a simile is always used for a good reason: it emphasises the point in question, produces its likeness-strengthening effect. To do so, it always has to exaggerate the tenor's feature by comparing it to the historical, social and situationally dependent (proto/stereotype or anti(proto/stereo)type in case of irony.

To envision the qualitative-quantitative interaction along the implied scale of gradation, representing a fragment of linguistic worldview, one might imagine an abstract scale of physical beauty, for example, in its widest sense, typical of an average European, comprising all possible aspects of physical state (Figure 1).

The polar notions of this scale would be represented by a bottom marker Quasimodo (the least beautiful) and an apex marker Aphrodite (the most beautiful) with several intermediate scale markers represented by less stereotypical beings, for instance: an ugly duckling, Marilyn Monroe and Miss Universe, etc. with a centre of the scale denoting a ground zero point of neuter evaluation. The movement vector from the lowest point to the highest one will indicate the pacing along the scale pitches by gradually increasing the ratio of "quantity" of beauty per unit. Thus, in simile His neighbour is as beautiful as Quasimodo the vehicle contains an extremely little amount of beauty indicating that the tenor referent is an ugly person. Not only 
does such simile characterise the tenor, but also reveals certain pragmatic intentions: The speaker is ironic if not downright sarcastic. By gradually "increasing the amount of beauty" in the vehicle, the tenor referent will cease to look like Quasimodo, she will undergo some quality transformations starting to be someone qualitatively different: rather resembling an ugly duckling, or with an even bigger amount of beauty Marilyn Monroe, or with even bigger amount of beauty she will look like Miss Universe until she reaches the apex of the scale (Aphrodite) possessing the largest amount of beauty and, therefore, being a qualitative opposite to the initial vehicle. Such quantitative-qualitative transformation totally changes not only the vehicle of the simile but the pragmatics of the statement. Thus, it becomes obvious that the change of quantity within simile decidedly leads to the change of quality; in other words, having had the amount of a possessed feature increased, the object starts a new level of its existence.

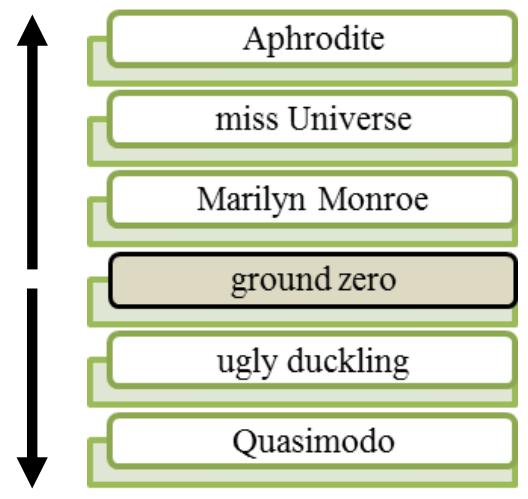

Figure 1. Abstract scale of quantity-quality interaction expressing gradability of physical beauty

From the perspective, where simile is by large a universal phenomenon showing some collective, historical as well as individual choices in terms of deciding on a vehicle, the hypothesis can be sufficiently confirmed by taking an entry from Sommer (2013), a dictionary compiled on the basis of the works of "writers with a special propensity for the simile" (Sommer, 2013, p. ix), as a sample empirical material for this paper. The gradual nature of simile as a linguo-cultural phenomenon in which philosophical categories of quantity, quality and relation that reveal themselves will further be demonstrated on "quiet as" similes, sampled by a continuous sampling method from a dictionary entry entitled SILENCE (Sommer, 2013)

Since the gradation scale of potential simile vehicles is purely subjective in nature, the sampled material is organised according to the author's subjective vision of the "quietness concentration" in every vehicle forming a certain graduated system, where a street of tombs in a buried city seems to be the most prototypical representation of quietness whereas a wooden-legged man on a tin roof seems to be the most anti-stereotypical representation of quietness (fig. 2).

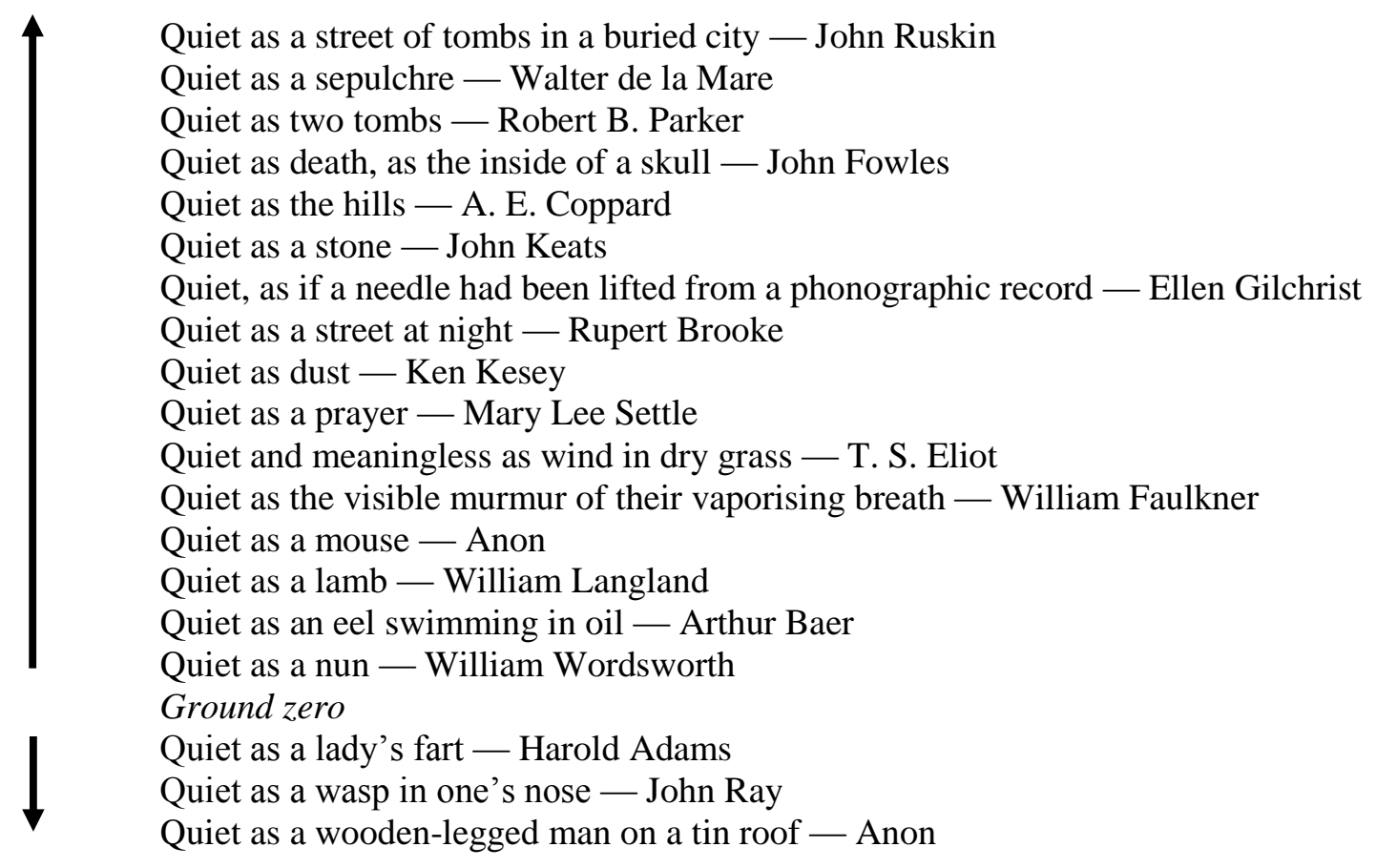

Figure 2. Abstract scale of quantity-quality interaction expressing gradability of quietness 
The actual ground zero point could be placed on the level between similes that imply making actual sounds/active movements (the ones marked with a down-arrow symbol: lady's fart, a wasp in a nose, a wooden-legged man on a tin roof) and those, not presupposing any sounds/active movements (the ones marked with an up-arrow symbol, that is, all others). The gradual movement along the up-arrow symbol will indicate the increase of "quietness concentration" in the vehicles: from the ones that nominate living beings potentially capable of producing a sound, thus displaying a lower degree of quietness; past those, which can otherwise vibrate under the influence of an air pressure, thus producing a sound of some (even very low) frequency, consequently, being more quiet than living beings; to the ones that are unable to do so, thus, displaying the highest possible degree of quietness.

\section{The application of the universal formula for a simile in terms of dialectics of quantity, quality and relation}

The polar similes will further be analysed to demonstrate the interaction of the three ontological categories in question by applying the universal formula for simile $A n \approx B^{n}$. Since the tenors are not indicated in the source of the empirical material, the noun event will be used as a tenor for these "event is as quiet as" similes. When one compares an event to a street of tombs in a buried city with the intention to highlight its quietness, s/he does so because s/he understands that the event (tenor, A) has the quality of being quiet (ground, $\mathrm{n}$ ) and a street of tombs in a buried city (vehicle, B) has the quality of being quiet (ground, $n$ ) as well, which makes them related $(\approx)$. Quietness is the only quality that is actualised in simile of all the others $a$ street of tombs in a buried city might possess (e.g. being decayed, aged, hidden, sacred etc.). Differently put, a simile is not about the combination of all possible qualities of a vehicle, but about the salient one. The same holds true for a tenor. So, speaking about the quantity of a certain quality means the salient quality of a tenor-vehicle pair. Juxtaposing an event and a street of tombs in a buried city, a speaker realises, however, that these two compared objects are different, that is, their quality in question is different because of its quantity: the "quantity of quietness" is so high in a street of tombs in a buried city that its immense concentration actually makes it a street of tombs in a buried city, whereas the concentration of quietness is much less in the event basically making it what it is. In other words, the quantity-quality ratio defines the compared objects. If the concentration of quietness could be significantly lessened in $a$ street of tombs in a buried city, the latter would become noisier and would cease to be a street of tombs in a buried city (in this way losing the grounds to be the simile vehicle), because if something incapable of moving is buried, it is absolutely quiet ipso facto. Likewise, if the amount of quietness were drastically decreased in the event under consideration, it would inevitably change its character and the latter would no longer be an extremely peaceful occurrence (in this way losing the grounds to be the "quiet as" congruous simile tenor). The dependence of quality upon quantity witnesses their dialectic unity in the juxtaposed items. Since the items are always compared in simile, the only way to exist within it is to be in relation to each other, thus involving the third ontological category into their integrity. In the formula $\mathrm{An} \approx \mathrm{B}^{\mathrm{n}}$ the relation is indicated by the $\approx$ symbol showing that the tenor and the vehicle are similar but not identical and it is the different concentration of a salient feature (marked by multiplication and exponentiation) that makes them different.

Contrary to a congruous simile, an ironic one is semantically more complicated because it is essentially pragmatically coloured. A speaker does not only impart the semantics of similarity between two items by means of it but also expresses his/her personal (often sarcastic) attitude to a compared object. Comparing a quiet event to a wooden-legged man on a tin roof would mean expressing an ironic or negative personal attitude to the happening due to the choice of an anti-stereotype as a simile vehicle, which is on the lowest point of the gradation scale. The irony (sarcasm) becomes possible because the tenor is compared to the opposite of the stereotype, the least expected vehicle. The lower the speaker moves along the gradation scale, the more ironic (sarcastic) s/he becomes: comparing the event to a lady's fart would describe a more or less hushed, if noticeable, occurrence, making the simile a little bit ironic. If the speaker were to choose a more anti-stereotypical object as a vehicle for quietness, comparing the event to $a$ wasp in one's nose, s/he would be describing a rather noisy happening restricted by cramped conditions, which could hardly be called quiet if the speaker were not fairly ironic. Choosing the furthest vehicle down from the ground zero point along the gradation scale would make the "quiet as" simile comparing the event to a wooden-legged man on a tin roof downright sarcastic, implying a very loud, boisterous occurrence. Thus, the further the anti-stereotypical vehicle is from the ground zero point of the gradation scale, the more sarcastic tone of the simile is.

The formula $\mathrm{An} \approx \mathrm{B}^{\mathrm{n}}$, being a universal simile formula, works for an ironic simile in the same way as it does for a non-ironic one. However, care should be taken to interpret the simile correctly, that is not to fail to comprehend the irony. This kind of problem was described in detail by Godbee and Porter (2013), Filik et al (2018), Giora et al (2018). In the case of the event being as quiet as a wooden-legged man on a tin roof, it 
is not quietness that the tenor-vehicle pair shares, but the absence of it. In fact, the items are compared because both of them are noisy. It is noisiness, an implied salient feature, not an explicitly stated one, that is the ground of this simile. Thus, whereas in the formula for the event is as quiet as a street of tombs in a buried city the symbol $n$ stands for quietness, in the formula for the event is as quiet as a wooden-legged man on a tin roof it stands for noisiness. Consequently, the event (tenor, A) has the quality of being noisy (ground, $\mathrm{n}$ ), a wooden-legged man on a tin roof (vehicle, B) has the same quality (ground, $\mathrm{n}$ ) in a greater concentration, that is, bigger quantity of it, which makes them related by similarity $(\approx)$. The dependence of quality upon quantity as well as vehicle gradability can be demonstrated along the downward movement vector as well: the decrease of noisiness in a wooden-legged man on a tin roof will mean its change into $a$ wasp in one's nose or even into a lady's fart if the reduction is too dramatic. The quantity-quality interdependence takes place due to the ability of the vehicle to be graded according to the amount of salient feature it possesses.

It could be argued, however, that the applied formula does not reflect an ironic character of a simile in any way. From a linguistic standpoint, it is not justified though mathematically possible. To mark the absence of an explicitly stated feature in a tenor-vehicle pair of an ironic simile, a negative value could be added to both parts of the equation: $-1 \cdot A n \approx-1 \cdot B^{n}$. The negative value of -1 added on both sides of the equation would not change the quantity-quality ratio of the tenor-vehicle pair, it would simply indicate the magnitude of a loss or deficiency. The absence of a linguistic necessity to do so, nonetheless, rests on the fact that simile a simile is not what is said, but rather what it means. Mostly, there is nothing accidental in the language, so the speaker explicates the opposite notion to a shared quality for a good reason in simile: s/he wants not only to highlight a certain quality of the compared items but also to express his/her attitude to the object that called for the comparison in the first place. Thus, during simile interpretation one should deal with the shared quality, be it explicitly or implicitly expressed, which is totally confirmed by the rules of mathematics applied to the formula $-1 \cdot \mathrm{An} \approx-1 \cdot \mathrm{B}^{\mathrm{n}}$ : The minus one factors are cancelled out on both sides of the equation leaving us with the initial formula $A n \approx B^{n}$.

Given that this paper is based on a limited amount of empirical material, a further investigation of ironic and non-ironic similes correlation as well as the peculiarities of their semantic representation would make an interesting issue for prospective research.

\section{Conclusions}

The gradable nature of a commonly shared feature enables a relative measurement of the ground in simile and is capable of showing the degree of its closeness or remoteness from the ground zero point. (Anti)proto/stereotypical images are located at the bottom and at the apex of the abstract scale of gradation. Gradability of the ground overlaps with the speaker's emotional evaluation showing a subjective way of measurement of a salient property. The transition of one notion, chosen to be a vehicle, into another is an interaction of quantitative and qualitative changes, which, on its way along the abstract scale, can pass through numerous intermediate phases. The choice of the (proto/stereo)type or anti-(proto/stereo) type to serve as a vehicle depends on the historical and social factors of the speaker. The findings of the paper can be used as a methodological basis for other linguistic investigations, especially those that promote an interdisciplinary approach. They can also be of use as a material for courses dealing with figurative language showing a fine line between semantics and pragmatics. The results can also serve as supporting data for the demonstration of linguistic worldview differences.

\section{References:}

Barnden, J. (2015). Metaphor, Simile, and the Exaggeration of Likeness. Metaphor and Symbol, 30 (1), 41-62. https://doi.org/10.1080/10926488.2015.980692

Bodujen de Kurtene, I. A. (1963). Kolichestvennost' v jazykovom myshlenii. Izbrannye trudy po obshhemu jazykoznaniju (T. 2) [Quantitaniveness in language thinking. Selected works on general linguistics (Vol. 2)]. (pp. 311-324). Moscow, USSR: AN SSSR.

Bondarko, A.V. (1996). Teorija funkcional'noj grammatiki. Kachestvennost'. Kolichestvennos' [Theory of functional grammar. Qualitativeness. Quantitativeness.]. SPb., Russia: Nauka.

Caws, P. (1993). Yorick's World: Science and the Knowing Subject. Berkeley Los Angeles Oxford.

Di Paolo, E., Cuffari, E., \& De Jaegher, H. (2018). Linguistic Bodies: The Continuity Between life and Language. Cambridge: MIT Press.

Duncombe, M. (2015). Aristotle's Two Accounts of Relatives in Categories7. Phronesis, 60 (4), $436-461$. https://doi.org/10.1163/15685284-12341292

Espersen, O. (1958). Filosofija grammatiki [Philosophy of grammar]. Moscow, USSR: Izdatel'stvo inostr. lit.

Filik, R., Howman, H., Ralph-Nearman, C., \& Giora, R. (2018). The role of defaultness and personality factors in sarcasm interpretation: Evidence from eye-tracking during reading. Metaphor and Symbol, 33 (3), 148-162. https://doi.org/10.1080/10926488.2018.1481258 
Giora, R., Cholev, A., Fein, O., \& Peleg, O. (2018). On the superiority of defaultness: Hemispheric perspectives of processing negative and affirmative sarcasm. Metaphor and Symbol, 33 (3), 163-174. https://doi.org/10.1080/10926488.2018.1481259

Godbee, K., Porter, M. (2013). Comprehension of sarcasm, metaphor and simile in Williams syndrome. International Journal of Language and Communication Disorders, 48 (6), 651-665. https://doi.org/ 10.1111/1460-6984.12037

Hood, P. M. (2004) Aristotle on the Category of Relation. University Press of America.

Il'ichjov, L., Fedoseev, P., Kovaljov, S., \& Panov, V. (1983). Filosofskij enciklopedicheskij slovar' [Philosophical encyclopaedic dictionary]. Moscow, USSR: Sov. jenciklopedija.

Lei, Z. (2016). Metaphor and Intercultural Communication. Andreas Musolff, Fiona MacArthur, and Giulio Pagani (Eds.). Metaphor and Symbol, 31 (4), 260-263. https://doi.org/ 10.1080/10926488.2016.1223464

Long, R. (2007). Aristotle on the Category of Relation (review). Journal of the History of Philosophy, 45 (1), 149-150. https://doi.org/10.1353/hph.2007.0014

Musolff, A.; MacArthur, F. \& Pagani, G. (Eds.). (2014). Metaphor and Intercultural Communication. London, UK; New Delhi, India; New York, NY; Sydney, Australia: Bloomsbury.

Nauta, L. (2007). Lorenzo Valla and the rise of humanist dialectic. Retrieved from http://www.rug.nl/staff/l.w.nauta/vallacambridge.pdf.pdf

Oleniak, M. (2018). Semantic representation of similes (based on the Ukrainian, English and Polish languages). Topics in Linguistics, 19(1), 18-32. https://doi.org/10.2478/topling-2018-0002

Panfilov, V. Z. (1977). Filosofskie problemy jazykoznanija: gnoseologicheskie aspekty [Philosophical problems of linguistics: gnoseological aspects.]. Moscow, USSR: Nauka.

Remijsen, B. (2014). The study of tone in languages with a quantity contrast. Language Documentation and Conservation, 8, 672-689. Retrieved 25 November 2018 from http://hdl.handle.net/10125/24620

Shvachko, S. (2007). Zasobi kvantifikaciï: lingvokognitivni aspekty [Means of quantification: linguocognitive aspects]. Sumy, Ukraine: SumDU.

Sommer, E. (2013). Similes Dictionary. Detroit, US: Visible Ink Press.

Sweet, H. (1872). King Alfred's West-Saxon Version of Gregory's Pastoral Care. London: Trübner \& Co.

Wilstach, F. J. (2017). A Dictionary of Similes (Classic Reprint). London, UK: Fb\&c Limited. 